\title{
Cuando las imágenes toman el archivo
}

\section{When images take the archive}

\author{
TIPO DE TRABAJO: Comunicación.
}

PALABRAS CLAVE:

Archivo, imagen, visibilidad, arte.

\section{KEY WORDS}

Archive, image, visibility, art.

\section{RESUMEN}

El paradigma del archivo se ha instaurado en los circuitos artísticos desde mediados del siglo XX como una práctica institucional. Sin embargo, la práctica artística del archivo se ha convertido en un "arte registral", como lo denominaría Isidoro Valcárcel Medina en 2008, ya que en muchos casos ha perdido el contacto con su posible intencionalidad e implicación. Por lo tanto, es necesario entender que su contenido, las imágenes, son las que conforman realmente los archivos y, por ende, deben tener prioridad en este género. Se presentan dos preguntas fundamentales al respecto para entender la diferencia: ¿qué podría ser el archivo?, y ¿qué podría ser una imagen?. Esta práctica artística del archivo sigue vigente hoy en día y corre el riesgo de continuar cometiendo errores que han estado presentes desde sus inicios. En consecuencia, es necesario acercarse al archivo desde las problemáticas que viene con el mismo, desde la obligación de seleccionar y olvidar, hasta las interpretaciones que se generan bajo este tipo de modelos de visibilidad. Así pues, la presente investigación trata de aproximarse a una mirada sobre el uso del archivo que prioriza otras formas de entender una imagen. De este modo, se buscará analizar la mirada sobre el concepto de la imagen y la visibilidad que adquiere cuando estructura un archivo.

\section{ABSTRACT}

The paradigm of the archive has been established in artistic circuits since the mid-twentieth century as an institutional practice. However, the artistic practice has become a "registry art", as what is called by Isidoro Valcárcel Medina in 2008, it has lost contact with their possible intentionality and involvement. Therefore, it is necessary to understand that their content, images, are what really make up the archives and, therefore, should have priority in this genre. Two fundamental questions are presented in this regard to understand the difference: What could archive be?, and what could an image be?. This artistic practice of the archive is still valid today and correlates the risk of continuing to make mistakes that were present at the beginning. Consequently, it is necessary to bring the archive closer to the problems that come with it, the obligation to select and forget, and the interpretations that occur in this type of visibility models. Therefore, this present investigation tries to approach a view on the use of the archive that prioritizes other ways of understanding an image. In this way, it will analyze the look on the concept of the image and the visibility that is acquired when an archive is structured.

\section{INTRODUCCIÓN}

Isidoro Valcárcel Medina fue claro: "Sepultemos el archivo, aunque no lo olvidemos" (Valcárcel, 2010). Este artista definió el archivo como una compartimentación, un almacén de una memoria de hecho y no de hechos. De este modo, afina llamándolo un arte registral en el cual su contenido está desprovisto de toda intencionalidad y es entendido como un listado de nombres y cifras.

La polémica de la práctica artística del archivo ronda en base a un uso indiscriminado del término y de la forma. Términos como fiebre o furor definen cómo esta práctica se ha institucionalizado y ha agarrotado la visibilidad del propio uso del archivo. Este es considerado como un dispositivo que suscita la sospecha sobre su propia naturaleza formal, estructurada en límites, y sobre las lagunas que se generan en base a estos contornos. Una compulsión de repetición que solo busca almacenar y recopilar, transformando 
todo su contenido en documentos legibles en base a una mirada conclusiva. Frente a este tipo de formulación de la forma archivística, otros han sido los que han tratado de replantearlo desde otras perspectivas. Un ejemplo de otro tipo de enfoque sería hacerlo desde una arqueología de los enunciados que, estos mismos, contienen desde la propia necesidad del olvido hasta su ausencia. Paradigmas como el del sistema del archivo o la propia fuerza anarchivistica del olvido, plantean visiones que deben volverse a poner en cuestión para encontrar otra mirada hacia la interpretación del archivo desde la práctica artística y, sobre todo, en la configuración de sus contenidos.

La presente investigación trata de encontrar un enfoque en el que el contenido de los archivos, las imágenes, vuelvan a ser el centro de la mirada al emplear la forma archivística. Por lo tanto, la hipótesis que se maneja es la posibilidad de entender el archivo desde sus imágenes y no el de emplear unas imágenes para conformar un archivo. Para ello, es necesario preguntarse sobre las probabilidades de posibilidad que otorgan los archivos como contenedores de las imágenes y, de este modo, alejarlos de la osificación sobre la que se suele trabajar al plantear un archivo desde la práctica artística. Así pues, los objetivos que se persiguen se organizan alrededor de establecer una visión que facilite la comprensión del desarrollo de los conceptos de archivo e imagen tratando de argumentar la relación que se crea entre ambos.

\section{METODOLOGÍA}

La metodología empleada para este trabajo viene a raíz del estudio de los autores que han planteado desde la cuestión sobre el contexto que envuelve al archivo como un estudio de las imágenes en particular. El enfoque llevado a cabo para este caso lo da el contexto sobre el que se está investigando el planteamiento: la formación en arte. Así pues, se precisa de una metodología basada en la investigación artística que versa sobre el estudio de sus prácticas vinculadas al paradigma del archivo y, además, en el análisis recogido de las reflexiones que varios autores han reflejado en su propio trabajo desde ámbitos que van desde la filosofía a la historia del arte.

Esto requiere, por tanto, de estrategias propias de la investigación artística de carácter cualitativo. Para este trabajo en concreto, se analizarán hermenéuticamente los textos y discusiones que han propiciado un contexto de debate con respecto de los objetos de estudio que aquí se plantean. Sin embargo, y debido a la naturaleza de este trabajo en particular, será necesario interpretar los datos desde una postura que favorezca la interrelación de las imágenes puestas en común. Cómo se desarrollará más adelante, el montaje como herramienta será imprescindible para encontrar ejemplos que, desde la práctica artística y el empleo de la relación heterogénea de su contenido, refuercen otras conexiones con el archivo y el contenido de los mismos. De igual manera que la concepción del museo imaginario (Malraux, 2017), se trata de encontrar otras relaciones entre las imágenes que acerquen la experiencia individual desde otras perspectivas al archivo. La finalidad, por lo tanto, es tratar de hacer una posibilidad de arqueología (Foucault, 2017) hacia las imágenes que muestre las capacidades de lo visible y lo decible mediante la forma del archivo.

\section{Del archivo a las imágenes}

Ana María Guasch estipula la propuesta de una organización que ya implicase la palabra "archivo", que viene del llamado Provenienzprinzip o "principio de procedencia" en las propuestas del historiador Philipp Ernst Spieß, pero estas no serán plenamente implantadas hasta el proyecto de reordenación de los Archives du Royaume y de la Bibliothèque impériale por Natalis de Wailly a finales del siglo XIX (2015, p. 16). El "principio de procedencia" estructuraba los archivos por su origen y no se clasificaban, por ende, por su contenido. De este modo, los archivos, a priori, eran espacios neutros que se clasificaban por su procedencia siendo gestionados como meros documentos y registros. Por lo tanto, los archivos eran espacios organizados con documentos o restos que se transforman en fragmentos con lo que estructurar la historia. Guasch, además, describe cómo el historiador Leopold von Ranke trató de producir relatos de historia mediante el archivo, siendo este el único punto de partida. Se hacía, por lo tanto, un trabajo con el pasado que trataba de organizar los relatos a través de sus fragmentos.

Rastreando unos inicios en el uso del archivo más allá de la biblioteca, Guasch propone el nombre de una serie de trabajos que denomina como protoarchivos. Estos se hacen desde de la práctica literaria como lo es el Libro de los Pasajes de Walter Benjamin iniciado en 1927, desde la práctica artística con los primeros archivos conseguidos tras la fotografía en serie de autores como Eugène Atget o August Sander, pero será desde la práctica historiográfica donde se encuentran las bases que proponen un ejemplo para la implicación sobre las imágenes dentro de un archivo. El historiador del arte Aby Warburg gestiona con su trabajo del Atlas Mnemosyne, iniciado en 1925, un archivo "visual" de relaciones entre diferentes documentos (desde fotografías a textos) tratando de encontrar gestos comunes a través del tiempo. Warburg acuña para ello el concepto de engrama cultural, entendiéndolo como las huellas de lo que queda de cada cultura, siendo impresas cómo registro sobre las imágenes que producen. Se plantea, de este modo, un archivo visual atravesado por las heterogeneidades y las discontinuidades generando un conjunto de relaciones subjetivas lejos de un orden cronológico. Walter Benjamin plantea, a su vez, esta nueva figura del historiador-arqueólogo en el que el objeto de estudio es el análisis del fragmento (Guasch, 2015, p. 25). Por ende, el archivo se convierte en una herramienta de análisis formada en base a una agrupación subjetiva de los fragmentos recopilados y puestos en común bajo un determinado marco. 
Estos marcos se convierten en estructuras de multiplicidades relacionales de datos con los que generar los discursos a través de los trabajos artísticos. El artista se convierte, mediante el archivo, en un historiador (Godfrey, 2007). El giro etnográfico que adopta el arte a mediados del siglo XX se debe a la comprensión del artista como un sujeto social que entra, por lo tanto, en el campo de la antropología para analizar la cultura (Foster, 2016). El archivo se entronca, desde este momento, con la práctica artística conceptual y comienza a institucionalizarse. Al igual que con Atlas Mnemosyne, la práctica artística se interesará por la recuperación de la memoria y sobre el cuestionamiento de las condiciones en las que se escriben los relatos. El archivo, a través del arte, se aleja de su origen como registro del tiempo contingente. En esta misma época, Michel Foucault reflexionará sobre el archivo describiendolo como la ley de lo que puede ser dicho, siendo este además incontorneable debido a que solo se puede dar por fragmentos (2017, p.171). Propondrá, para ello, la arqueología como método para analizar el archivo, siendo este un trabajo interno del mismo que se adentra en su interior y organiza, ordena y estructura describiendo relaciones y elaborando los discursos. Por ende, sería el contenido fragmentado del archivo lo que estructuraría los discursos que se pudiesen proponer desde el mismo.

El arte, en adelante, se servirá del archivo como contenedor de recopilación de discursos vinculados con el nuevo papel del artista como etnólogo. Esto hace que las propuestas conceptuales que pensaban alrededor del archivo en los años sesenta se llegue a la concepción del archivo como una base de datos, estos se harán en base a relaciones rizomáticas de combinación y multiplicidad a partir de los años ochenta (Spieker, 2008). Se podría comprender el archivo como un dispositivo, entendiendo un dispositivo como un aparato en el cual las relaciones de subjetividad de los seres humanos los convierten, a estos, en sujetos culturales vinculados a su entorno (Agamben, 2015). El archivo se emplea como un instrumento para cuestionar la condición histórica, el concepto de autoría, la representación, replantear la memoria o reflexionar sobre la estructuración de subjetividad (Guasch, 2013, p. 179). Con estos y otros motivos, el dispositivo archivístico ha sido foco de atención de varias disciplinas que han tratado de reflexionar tanto entorno al mismo como sobre su uso. La definición de Isidoro Valcárcel Medina respondería a un furor de archivo, como lo llama Suely Rolnik (2009), que se ha limitado en continuar desde la práctica artística un uso del contenedor como una mera base de datos. El riesgo se convierte en un perder la conexión sobre la propia naturaleza del archivo. Por ello, regresar al mismo mediante su contenido parece una de las vías con las que encauzar el debate sobre su uso.

\section{Tomar posición desde la imagen}

No perderse en la fiebre del archivo (Derrida, 1997) y aproximarse, tanto a su contenido como a las ausencias del mismo, requiere implicar la experiencia individual. Georges Didi-Huberman describe esta tarea desde la concepción de tomar posición como un trabajo de situarse en el tiempo, donde apelar a nuestra memoria e implicarse con ella (2013). El objeto de estudio que le sirve para describir este posicionamiento lo hará con la obra desde el exilio de Bertolt Brecht y, sobre todo, con su libro Kriegsfibel. Brecht, en ese caso en particular, recorta imágenes de los medios de comunicación durante la Segunda Guerra Mundial y los agrupa en un libro describiendo el contenido de cada imagen mediante un epigrama de cuatro versos para hacer hablar a las imágenes. Huberman describe el proceso del trabajo de Brecht explicando la implicación de este con su momento histórico y dejándose afectar por la información que recopila. Trata, por tanto, de deconstruir para luego remontar, por su propia cuenta y, de este modo, decir mejor (2016). Plantea a su vez, "una red de anacronismos salidos de sus propios montajes o construcciones de hipótesis"(2013, p. 20). Así pues, el montaje de los fragmentos que va recopilando Brecht constituyen una visión de su entorno mediante la estructuración de un archivo en forma de libro.

Por otro lado, para poder continuar, cabría hacerse primero la pregunta sobre qué se considera una imagen actualmente. Parte de este debate entorno a la imagen se ha llevado desde la intención de realizar una ontología de la propia imagen (García, 2011). Se trataría de rastrear desde su etimología hasta los distintos conflictos entorno a la misma, reflejados en las reacciones que han llevado a la imagen a sus diferentes interpretaciones, analizando posiciones que van desde la iconodulia hasta la iconoclastia (Freedberg, 2015). La imagen, por lo tanto, ha sido un elemento de conflicto que ha llevado al órgano de la vista y a la mirada desde la confianza a la desconfianza y viceversa (Garcés, 2013). Por ello, parte de la problemática actual es actuar sobre la misma desconfianza que provocan las imágenes (Baudrillard, 2016) o la sobreproducción de las mismas. Sin embargo, hay otros autores que no ven que el problema verse sobre el exceso de imágenes, sino que sería más bien un problema de selección de las mismas y la posición que se toma frente a ellas. Jacques Rancière describe cómo, esta misma queja sobre el exceso, ya se discutió en el siglo XIX en el que se acusaba de que las clases populares no serían capaces de enfrentar los mensajes que proliferaban gracias a los nuevos medios de producción (2017). Es en esta línea de debate donde las imágenes cobran otro protagonismo desplazando la discusión desde la ontología hasta las formas de producción.

Michel Melot desarrolla una historia de las imágenes que está estrechamente vinculada con sus medios de producción (2010). Con esta misma idea, Walter Benjamin comenzó uno de sus más famosos ensayos tratando de exponer el materialismo histórico como un fundamento para los cambios entre los medios que se emplean para la creación y difusión de imágenes (2016). En esta misma línea, Hans Belting desarrolla una antropología en la que las imágenes son sus artefactos de estudio convirtiéndose, por tanto, en objetos de conocimiento (2012, p. 15). Belting específica también que "la imagen tiene siempre una cualidad mental y el medio siempre una cualidad material" (2012, p. 39). Se puede observar que parte del debate entorno a la imagen tiene un componente en el que el medio es imprescindible para la representación de la imagen, la forma se hace necesaria para que sea visible mediante un cuerpo, entendido como un medio. Belting insiste en que incluso una imagen puede percibirse con una nueva mirada si es a través de un nuevo medio 
(2012, p. 12), tal y como Walter Benjamin también defiendió anteriormente (2016). En este punto, Belting propone una historia de las imágenes que tenga en cuenta los medios de reproducción y una implicación en las imágenes. Para ello, comenta como Aby Warburg, cansado de una "historia del arte estetizante", buscó otros modos de acercarse a la imagen y lo hizo a través del giro antropológico junto al concepto de las migraciones. Estas migraciones serían relaciones interculturales, intermediales y anacrónicas que distinguen un tiempo en cuanto al pasado de la imagen y el presente en el que es percibida (Didi-Huberman, 2008). Es, por tanto, imprescindible para estos autores, centrarse en la imagen desde sus posibilidades de producción y el contexto en el que son percibidas. Un ejemplo del potencial intercultural e intermedial de las imágenes sería el exhaustivo desarrollo que propone Serge Gruzinski. Este se basa en las políticas de la imagen, en el que analiza la acción y la reacción frente a estas, del México colonial y barroco (2003).

Por lo tanto, la imagen es un concepto extenso que se ha tratado de entender desde posturas ontológicas y de producción, entre otras que exceden este análisis. Como un posible resumen de la cuestión, W.J.T. Mitchell propone un esquema sobre las diferentes maneras en las que la imagen se ha entendido a lo largo del tiempo. Estas formas van ligadas desde la materialidad, como las gráficas pasando por las ópticas y perceptivas, hasta llegar a las formas inmateriales como pueden ser las mentales e incluso las verbales (2011, p. 110). Las imágenes se entienden como significantes de transmisión de significados, siendo los elementos imprescindibles que conforman los contenedores en las que pueden ser recopilados. Por lo tanto, se observa el potencial que tienen las imágenes para influir en su contexto pero que, aún así, requieren de la posición de los individuos sobre estas. Para ejemplificar lo anterior mencionado se podría exponer la pintura de Gerhard Richter Taunte Marianne (1965). Esta misma podría ser capaz de afectar e implicar al individuo si se conociese que este retrato, aparentemente inocente, trae consigo el relato de cómo la tía del artista fue asesinada por el régimen nazi bajo los programas eugenésicos. Del mismo modo, podemos entender como el trabajo videográfico de Jean-Luc Godard Histoire(s) du cinèma (1998) o, más recientemente, Le livre d'image (2017) cómo son las propias imágenes recopiladas y montadas las que conforman un enorme archivo que trabaja en función de su contenido y no al contrario, generando otra visibilidad a través del fragmento y el montaje, proponiendo de esta manera otras posibilidades de relatos.

\section{CONCLUSIONES}

Recuperando la hipótesis planteada, se confirma que las imágenes estructuran los archivos y que han sido las diferentes metodologías empleadas para estudiar las imágenes las que han ido variando la mirada que se ha tenido sobre las mismas. A pesar de la concisión con la que se ha tenido que abordar la argumentación, se pueden relacionar el cómo han sido conceptos como historia, memoria, huella, fragmento, visibilidad, entre otros, los que han hecho que, a través de las prácticas artísticas, se hayan construido otras relaciones frente a lo visible y lo invisible, encontrando en la forma del archivo un aliado que permite otras analogías de construcción de imaginarios. Sin embargo, es necesario poder comprender que sin las imágenes no habría archivos y se ha observado cómo estos mismos no han sido posibles sin el material con el que crearlos. Por lo tanto, se entiende como ya no solo hay que centrar el análisis y la mirada en las imágenes, sino también tomar posición frente a ese contenido e implicarse en su contexto. Es, de este modo, una labor de recuperación de la mirada con la imagen como herramienta pese a todo (Didi-Huberman, 2016). Un ejemplo de este tipo de planteamientos lo expone Marina Garcés con lo que llama una visión periférica (2013). Una mirada que busca en lo desenfocado de lo enfocado, el mismo lugar sobre el que se generan los archivos. Se verifica por tanto, y a través de los ejemplos propuestos en el escrito, la dependencia de los archivos con las imágenes. Estas serían los verdaderos elementos con las que poder establecer nuevos paradigmas y encontrar, en los ángulos ciegos, el rastro de algo que aún precisa de nuestra atención (Garcés, 2013, p. 114).

\section{FUENTES REFERENCIALES}

Agamben, G. (2015). ¿Qué es un dispositivo?. Barcelona: Anagrama.

Baudrillard, J. (2016). Cultura y simulacro (12a ed.). Barcelona: Editorial Kairós.

Belting, H. (2012). Antropología de la imagen (3ªed.). España: Katz Editores.

Benjamin, W. (2016). La obra de arte en la época de su reproducción mecánica (6a ed.). Madrid: Casimiro libros.

Derrida, J. (1997). Mal de archivo: una impresión freudiana. Madrid: Trotta.

Didi-Huberman, G. (2008). Ante el tiempo. Buenos Aires: Adriana Hidalgo editora. 
Didi-Huberman, G. (2012). Arde la imagen. Oaxaca: Ediciones Ve.

Didi-Huberman, G. (2013). Cuando las imágenes toman posición. Madrid: Machado Grupo de Distribución.

Didi-Huberman, G. (2016). Imágenes pese a todo (6a ed.). Barcelona: Espasa Libros.

Foster, H. (2016). El retorno de lo real: la vanguardia a finales de siglo. Madrid: Ediciones Akal.

Foucault, M. (2017). La arqueología del saber (4ạ ed.). México: Siglo XXI Editores.

Freedberg, D. (2009). El poder de las imágenes: estudios sobre la historia y la teoría de la respuesta. Madrid: Ediciones Cátedra.

Garcés, M. (2013). Un mundo común. Barcelona: Edicions Bellaterra.

García, A. (2011). Filosofía de la imagen. Salamanca: España. Ediciones Universidad de Salamanca.

Godfrey, M. (2007). The Artist as Historian. October 120 (primavera 2007), pp. 140-172.

Gruzinski, S. (2003) La guerra de las imágenes: Desde Cristobal Colón a Blade Runner (1492-2019). Madrid: S.L. Fondo de Cultura Económica de España.

Guasch, A. M. (2013). Arte y Archivo, 1920-2010: Genealogías, tipologías y discontinuidades (2ª ed.). Madrid: Ediciones Akal.

Malraux, A. (2017). El museo imaginario. Madrid: Ediciones Cátedra.

Melot, M. (2010). Breve historia de la imagen. Madrid: Siruela.

Rancière, J. (2017). El teatro de imágenes. En: Jaar, A. (Ed.), La política de las imágenes. Santiago de Chile: ediciones/metales pesados.

Rolnik, S. (2009). Furor de archivo. Estudios visuales: Ensayo, teoría y crítica de la cultura visual y el arte contemporáneo, 7, 115-129.

Spieker, S. (2008). The Big Archive: Art from Bureaucracy. Londres: The MIT Press.

Valcárcel Medina, I. (2010). El objeto y el fin. En: Estévez González, F., y Santa Ana, M. (Eds.), Memorias y olvidos del archivo. Madrid: Outer Ediciones.

William J. T., M. (2011). ¿Qué es una imagen?. En: A. García (Ed.), Filosofía de la imagen. Salamanca, España: Ediciones Universidad de Salamanca. 